Instructions for authors, subscriptions and further details:

http://brac.hipatiapress.com

\title{
El Pensamiento Lateral del Arte Contemporáneo. Josefa Tolrà, Médium y Artista (1880-1959)
}

Pilar Bonet ${ }^{1}$

1) Facultad de Bellas Artes. Universidad de Barcelona. España

Date of publication: October $3^{\text {rd }}, 2014$

Edition period: October 2014-February 2015

To cite this article: Bonet, P. (2014). El pensamiento lateral del arte contemporáneo. Josefa Tolrà, médium y artista (1880-1959). Barcelona, Research, Art, Creation, 2(3), 256-276. doi: 10.4471/brac.2014.13

To link this article: http://dx.doi.org/10.4471/brac.2014.13

\section{PLEASE SCROLL DOWN FOR ARTICLE}

The terms and conditions of use, except where otherwise noted, are related to the Open Journal System and to Creative Commons Attribution License (CCBY). The indication must be expressly stated when necessary. 
BRAC - Barcelona Research Art Creation. Vol. 2 No. 3, October 2014, pp. 256-276

\section{Lateral Thinking in Contemporary Art. Josefa Tolrà, Medium and Artist (1880-1959)}

Pilar Bonet

University of Barcelona

(Received: 16 June 2014; Accepted: 12 August 2014; Published: 3 October 2014)

\section{Abstract}

We are attracted to the creative drive of marginal authors. The creativity that suddenly wakes up and after the experience of altered states of consciousness. Throughout the twentieth century, we have studied non-rational forms of creation, the art of the mentally ill, those suffering social exclusion, visionaries and creators of mediumship world. Oddities art history to be kept under observation and elusive unorthodox reason. Today we live an extraordinary recovery of productions that do not meet the official canons or academic processes of art and challenges posed to us about the idea of art, beauty, creation and the role of art history. The author Josefa Tolrà is a new case study, beyond the terms Art Brut or outsider art: a case of mediumistic art.

Keywords: art mediumship, spiritualism, theosophy, occultism, drawing fluidic. 
BRAC - Barcelona Research Art Creation. Vol. 2 No. 3, October 2014, pp. 256-276

\section{El Pensamiento Lateral del Arte Contemporáneo. Josefa Tolrà, Médium y Artista (1880-1959)}

Pilar Bonet

Universidad de Barcelona

(Recibido: 16 Junio 2014; Aceptado: 12 Agosto 2014; Publicado: 3 October 2014)

\section{Resumen}

Nos atrae la pulsión creativa de los autores marginales. La creatividad que se despierta de forma repentina y tras la experiencia de estados alterados de la conciencia. A lo largo del siglo XX hemos estudiado formas no racionales de creación, el arte de los enfermos mentales, los que sufren exclusión social, los visionarios y los creadores del mundo mediúmnico. Rarezas que la historia del arte mantiene en observación por ser heterodoxas y esquivas a la razón. Actualmente vivimos una extraordinaria recuperación de producciones que no responden a los cánones oficiales ni a los procesos académicos del arte y que nos plantean retos acerca de la idea de arte, belleza, creación o el papel de la historia del arte. La autora Josefa Tolrà es un nuevo caso de estudio, más allá de los términos art brut o outsider art: un caso de arte mediúmnico.

Palabras clave: arte mediúmnico, espiritismo, teosofía, ocultismo, dibujo fluídico. 


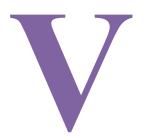

irginia Woolf, en una carta a su marido poco antes de su suicidio el 28 de marzo del 1941 en Kensington, escribió sobre su confuso estado mental remarcando que «empiezo a oír voces y no puedo concentrarme». La experiencia de las voces o la visión de seres de luz, en el caso de la poetisa Alejandra Pizarnik eran los Cuerpos luminosos de su poema, convoca la extraordinaria creatividad de autoras como Camille Claudel, Unica Zürn, Frida Kahlo, Hilma af Klint, Louise Bourgeois, Leonora Carrington o Remedios Varo, entro otras ya reconocidas. La depresión y el proceso creativo ha estado estudiado en casos de autores y autoras dedicados a la literatura y el arte como experiencia, más allá de la razón y la funcionalidad existencial, de enorme potencialidad creativa. Estudios e interpretaciones que documentan el nuevo interés de la producción artística contemporánea por lo oculto o lo negado, en su sentido más reivindicativo y político, como una nueva forma de «resistencia individual», en palabras de Chus Martínez, curadora de la exposición y el catálogo La gran transformación. Arte y magia táctica, presentada en Rotterdam el 2008.

Las relaciones entre arte y estados alterados de la razón, arte y espiritualidad, arte y ocultismo, arte y sanación o arte y mediúmnidad, ponen de manifiesto la necesidad de vincular la producción artística con lo oculto, lo maravilloso, lo utópico, la mítico y lo insólito como una forma de acercarse a un nuevo espacio de conocimiento que el pensamiento lógico de la era moderna desterró. Entre la heterogeneidad de materiales de estudio, las obras que surgen de estos peculiares estados de conciencia y experiencia existencial nos proponen una revisión de la historiografía contemporánea.

No deja de llamar la atención el interés que este tema ha despertado en los últimos años, y seguramente forma parte de una especial proliferación de nuevos acercamientos y consideraciones acerca de la crisis del pensamiento moderno. Tanto desde la crítica a las propuestas formalistas sobre las que se construyó la historia del arte desde mediados del siglo XX, como en las nuevas direcciones del pensamiento filosófico actual más cercano a las alternativas críticas y las actitudes antagonistas que a los valores hegemónicos que han construido el discurso de la civilización moderna y su doctrina de progreso. 


\section{¿Por qué la Investigación y Difusión de los Trabajos de una Autora Desconocida Llamada Josefa Tolrà?}

La Bienal de Venecia presentó en la edición 2013 una muestra de trabajos artísticos y autores vinculados al mundo del espiritismo, la mediúmnidad, el esoterismo y la inteligencia no racional. La propuesta del comisario Massimiliano Gioni puso atención en aquellos parámetros de representación y de experiencia estética que no forman parte de los estilos y lenguajes académicos, en un intento de releer la historia del arte y de la cultura de Occidente con producciones que, en su hipótesis de trabajo, también configuran el ámbito del saber, la gran enciclopedia de nuestro mundo. En este importante evento contemporáneo, el arte defuera el canon institucional, las imágenes mistéricas, la mediúmnidad y los autores diletantes fueron puntos de atención crítica y dispositivos para releer no sólo la historia del arte contemporáneo, sino la construcción de una cultura hegemónica basados en la razón del cogito ergo sum.

$\mathrm{Y}$ al mismo tiempo que se celebraba la Bienal veneciana, el gobierno sueco rescata de un olvido programado la figura de la artista Hilma af Klint (18621944) en una magnífica exposición y catálogo bajo la dirección de Iris Müller. ${ }^{2}$ Una autora vinculada al mundo visionario, como paradigma de una vocación artística más allá de los cánones de las vanguardias históricas de principios del siglo XX y ella misma preconizadora. Hilma af Klint se convierte, sin duda, en una gran apuesta por las nuevas lecturas sobre la historia del arte europeo, sobre los paradigmas estéticos y la producción de mujeres artistas. Las extraordinarias obras de Hilma af Klint, dibujos y pinturas, pueden interpretarse desde los marcos de la abstracción vanguardista, pero también desde la arquitectura de una imaginación conectada con las fuerzas espirituales del cosmos y elaborada en una cadena de relaciones entre mujeres que dibujando en grupo aportan imaginarios visuales a una experiencia estética nada convencional (Bonet, 2014).

Uno y otro caso, entre muchos otros, son ejemplos del renovado interés que anima la posibilidad de una mirada colateral de la historia del arte del siglo $\mathrm{XX}$. De una voluntad de relectura sobre las coordenadas de legitimación de la producción visual que hemos consensuado como «arte». Ahora, el siglo XXI reclama nuevos lugares y actitudes para abordar el conocimiento del mundo moderno que fenece.

La fascinación por el mundo no material, por las visiones esotéricas, la experiencia psíquica o los trabajos no ortodoxos se activan en todos los 
campos del saber y en especial desde el mundo del arte. Si Hilma af Klint representa una gran apuesta de la cultura sueca por interpretar y legitimar una artista nada convencional, pero de gran fuerza constructiva en sus obras y enorme potencialidad espiritual en sus vivencias, en nuestro territorio la figura de Josefa Tolrà i Abril (1880-1959) la médium de Cabrils, aporta nuevos materiales de lectura sobre este mismo centro de atención crítica. La reciente exposición y el catálogo dedicado a las obras de esta autora nos permite reactivar las lecturas e interpretación de este campo de producción artística. ${ }^{3}$

El dibujo, la escritura y los bordados son materiales de trabajo para esta autora catalana, alejada del mundo del arte y la literatura, casi analfabeta y en cambio portadora de una gran emoción espiritual y creativa. Josefa Tolrà es una figura desconocida e insólita, a pesar de que actualmente muestra sus dibujos en tres museos internacionales de arte contemporáneo, y que reclama un esfuerzo de investigación que aporte una interpretación sobre su producción, contexto y el factor mediúmnico de su trabajo.

Esta clarividente artista, cuyo legado sigo investigando e interpretando desde hace varios años, escribía y dibujaba como experiencia de sus momentos de trance mediúmnico, en conexión con los seres de luz que siempre le acompañaban. Su vida estuvo marcada por grandes pérdidas, la muerte de sus dos hijos, y gozosas experiencias extrasensoriales que le permitían visionar y dialogar con hermanos espirituales. Aunque nunca abandonó su pueblo natal, Cabrils, su vida fluye por diversas rutas en el tiempo y los contextos de la humanidad a través de su potencial interior. Josefa Tolrà, sin estudios ni formación artística o literaria, escribía y dibujaba personajes y escenarios que nunca conoció, disertaba sobre temas que no estudió y respondía a preguntas sobre teoría de los colores o la función de la pintura cuando los artistas del grupo Dau al Set o el crítico Alexandre Cirici Pellicer la visitaban. Ella misma firmaba sus dibujos como mediadora mecánica, humilde transmisora entre el mundo espiritual y el material. Sus dibujos evocan esas otras realidades de una vivencia multidimensional donde presente, pasado y futuro, el ahora y el más allá conviven, haciendo oídos sordos al pensamiento racional que los estigmatiza.

Para esta artista, que ahora la imprevisible posteridad hace emerger del olvido (en palabras robadas a Duchamp), el genio científico de Marconi, la poesía de Verdaguer o la bondad de Jesús comparten escala de valores, de la misma manera que los planetas y las diosas de fuego propician la comprensión de la energía fluídica que todo lo mueve y regenera. Sin presión literaria ni estética esta mujer humilde y bondadosa escribió sobre geología o filosofía, 
redactó novelas, poemas, recetas sanadoras e ilustró los textos con retratos de personajes históricos, fantasías astrales, escenas bíblicas o paisajes con la figura del geólogo y el jardinero (figura 1). Nunca sufrió marginación ni recibió tratamiento psiquiátrico, su creatividad invocadora y reveladora nos enseña aquello que los ojos no ven pero el espíritu verifica. Todo aquello que la civilización racionalista y maquinista olvidó en su loco trasiego de producción y consumo.

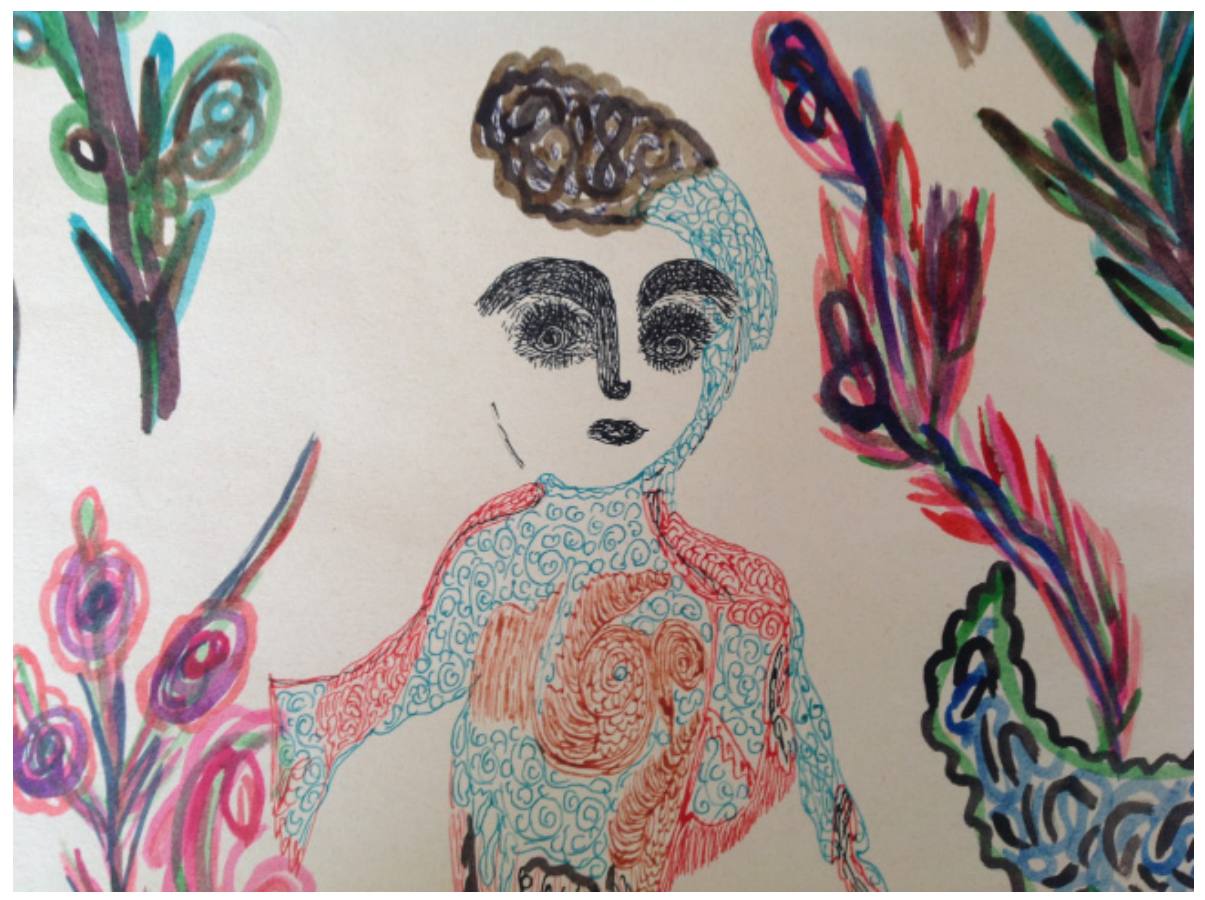

Figura 1. Dibujo fuerza fluídica. El geólogo y el jardinero, 1955 (detalle). Acuarela, pluma y bolígrafo sobre papel, 46 x $60 \mathrm{~cm}$. Colección particular Maria Tolrà

Artistas como Josefa Tolrà que se distancian de la cultura hegemónica, el racionalismo científico e industrial o la religión institucionalizada, se convierten en una vía de experiencia ciertamente antagonista y de marcada conciencia social. Para Josefa Tolrà, cristiana y espiritista, aquello realmente importante es el progreso espiritual, la justicia social, la paz y la poesía. Es decir, todo aquello que se contrapone a los valores materialistas y especulativos de la vida 
y del arte en una perspectiva de lujo y espectáculo. Nunca comercializó sus dibujos ni cobró por sus recetas sanadoras, siempre antepuso el bien común a los intereses personales, veía el aura de las personas pero no las acosaba con su interpretación.

Ahora, más allá de apriorismos relacionados con los descriptores ya legitimados de art brut y outsider art, podemos pensar en nomenclaturas como la de un «arte mediúmnico», o quizás un «arte necesario»?

\section{Josefa Tolrà, Arte Mediúmnico}

Entre 1941 y 1959, Josefa Tolrà realizó más de un centenar de dibujos sobre papel, ilustró y escribió numerosas libretas, compuso poemas, transcribió textos y bordó mantones con formas fluídicas. Una actividad paciente y entregada que hacía en casa sin dejar de atender a la familia y a los vecinos que la visitaban para requerir su ayuda como vidente y sanadora. Mujer apacible, comenzó a dibujar para superar la enorme tristeza que le ocasionó la muerte de dos hijos varones, uno de ellos en un campo de refugiados tras la guerra: «solo cuando dibujo me siento en paz», decía en muchas ocasiones a sus familiares y vecinos. Jamás se quiso artista ni buscó el reconocimiento, dibujar era un antídoto contra el orden racional para superar el dolor existencial en un tiempo de pérdidas y nostalgia, en plena postguerra española. Sin estudios ni influencias artísticas, su obra es espontánea y, a la par, detallista, hecha en el ejercicio de la paciencia gráfica y la inspiración extrasensorial.

¿Artista y médium, o médium y artista? Es importante destacar que la historia de Josefa Tolrà está totalmente vinculada a su potencial de médium y clarividente. La documentación biográfica que nos facilita directamente la familia nos indica que sin esta experiencia psíquica no habría desarrollado su especial creatividad. La muerte de los hijos la sumió en una vertiginosa introspección, y aquí es donde gesta el inicio de una singular experiencia artística y literaria, inédita para una mujer de sesenta años que vive en una pequeña población rural de la comarca del Maresme. A raíz de este trance de duelo y depresión, entró en comunicación con seres de otra dimensión: los espíritus desencarnados, una energía fluídica que ella reconoce como parte del universo. Cuando toma conciencia de los «guías espirituales» que la acompañan, Josefa consigue una paz interior que canaliza a través de los dibujos y escritos que los «ángeles de la luz» le dictan. En alguna firma de las obras, se identifica como «una hermana que tiene la misión de trabajar en el dibujo y también de escribir con trasmisión de pensamiento», una mera 


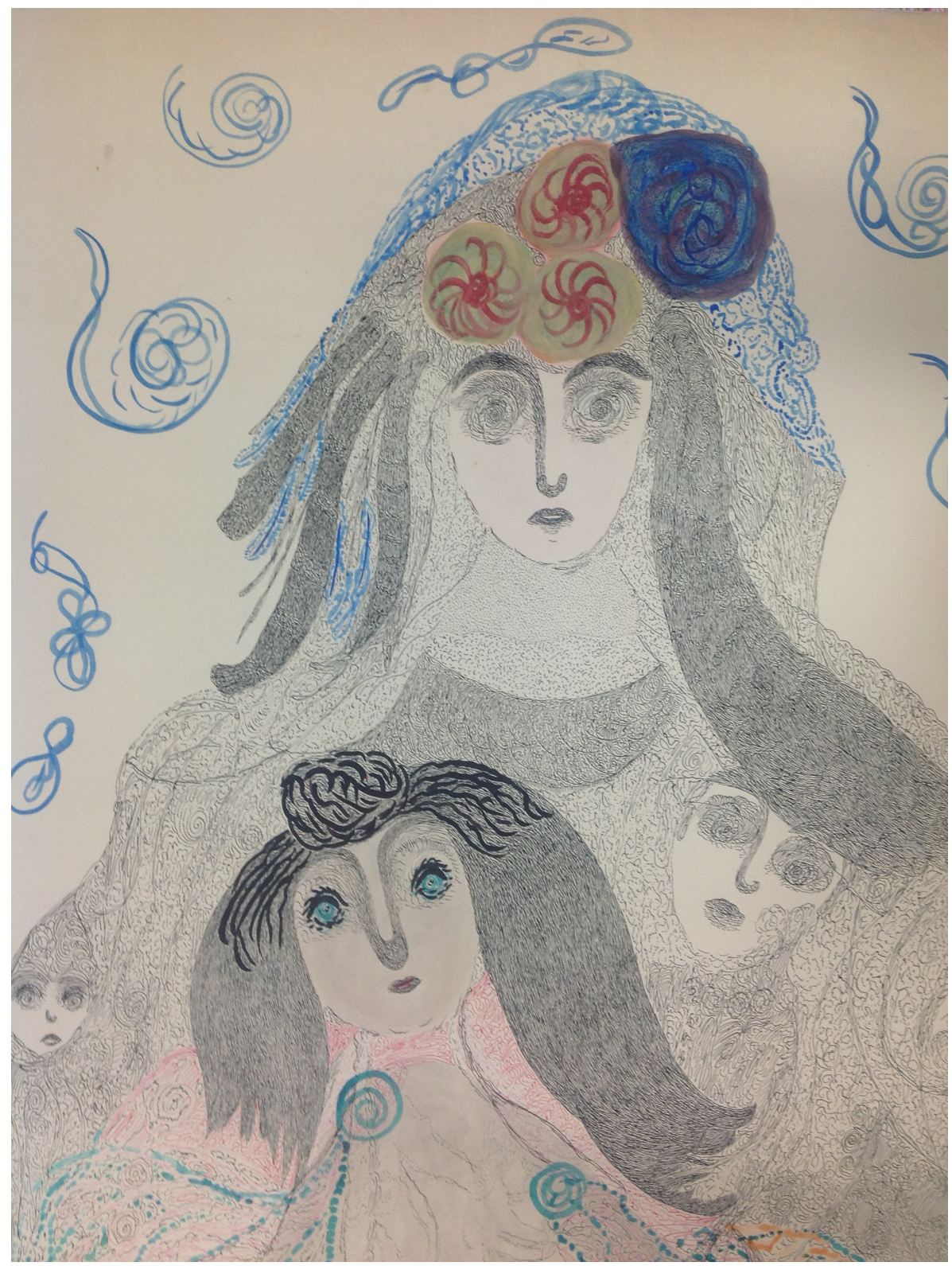

Figura 2. La gran teósofa, 1953 (detalle). Tinta, acuarela y rotuladores de colores sobre papel, 102 x $70 \mathrm{~cm}$. Museo Nacional Centro de Arte Reina Sofía 
canalizadora entre diferentes mundos. Sin duda, en esta actividad extrasensorial también influye la comprensión de la familia, en especial, los buenos consejos de su pariente Jordi Galbany, vinculado a círculos espiritistas, así como los vínculos con la teosofía, muy practicada en aquella época en Cataluña. En algunos escritos de las múltiples libretas que nos dejó, la propia Josefa define términos como «médium» o «teosofía» y en diversos dibujos firma como «JT médium», un léxico desconocido para quien no forma parte de estos círculos. Todas las señales nos aclaran el sentido de los dibujos y las experiencias que vive la autora, en el interior del espacio multidimensional que guía su potencial creativo y sanador. Josefa Tolrà ve el aura de las personas y, a través de ésta, puede ayudar a recomponer el equilibrio energético. La obra titulada La gran Teósofa (1953) (figura 2) es toda una evidencia de estos saberes y una maravilla gráfica, enraizada en una intuición directa y en el desarrollo espiritual como un camino para llegar al conocimiento de Dios.

Desde el siglo xix, y en especial tras la primera guerra mundial, se había extendido la práctica del espiritismo en toda Europa, lo que significó el interés por el ocultismo y la práctica de sesiones mediúmnicas. El espiritismo se vincula a videntes y clarividentes, quienes hacen de mediadores con los espíritus de los muertos. Pero los espiritistas no se dedican a predecir el futuro, aunque las personas con aptitudes de videncia pueden tener premoniciones. De hecho, el espiritismo no se considera ninguna religión sino una filosofía espiritualista que cree en la reencarnación y que se inició en París en 1857 con la publicación del primer libro de Allan Kardec, El libro de los espíritus. El Espiritismo vivió un extraordinario auge hasta el 1939. Paralelamente, el movimiento teosófico moderno estuvo encabezado por Helena Blavatsky y buscaba el desarrollo espiritual a través de la filosofía y la ciencia. El esoterismo y la teosofía se entrecruzaron con la incorporación del inconsciente en el imaginario individual y social. Las investigaciones médicas y biológicas de la época promovieron el estudio de los sueños, así como la liberación de la palabra, que recogería el psicoanálisis y que tendrían eco en artistas y escritores a través de nuevos lenguajes en la pintura, el dibujo o el texto, mediante asociaciones libres, el automatismo o la búsqueda de una nueva forma de expresión que aludiese a otras realidades no materiales. Adolf Wölfli fue diagnosticado con «demencia precoz» en 1895 y es un ejemplo de lo que hoy posiblemente sería cuestionado como enfermedad. Su ingreso en una clínica psiquiátrica ese mismo año le indujo a contar la historia de su vida en una biografía de más de veinte mil páginas, y a partir de 1899 empezó a dibujar. En su trabajo abordaba cuestiones como la repetición obsesiva, la auto- 
ficción y la promesa de otra identidad, recurrente en sus escritos. Su obra fue considerada por André Breton como una de las más significativas de la época y absoluta creatividad liberada de la razón. Todas estas referencias se gestan a la sombra de las indicaciones de la teósofa Helena Blavatsky (1831-1891), la autora del pensamiento fundacional de la Sociedad Teosófica, un movimiento filosófico-religioso y esotérico que opta por la búsqueda de la sabiduría divina a través de la filosofía y la ciencia. Ella aseguraba haber sido el canal para que el Maestro Morya le dictara La doctrina secreta. El movimiento teosófico tuvo una gran arraigo en Barcelona a finales del siglo XIX gracias a las ediciones de Ramon Maynadé. Este mismo personaje visionario puede ser la figura de la magnífica gran teósofa que Josefa Tolrà dibuja en 1953.

Josefa Tolrà llega a la creación desde la mediumnidad, como otros casos de mujeres que, sin formación artística, dibujan y bordan enigmáticos escenarios astrales y practican la sanación: la visionaria Aloïse Corbaz (1882-1965),

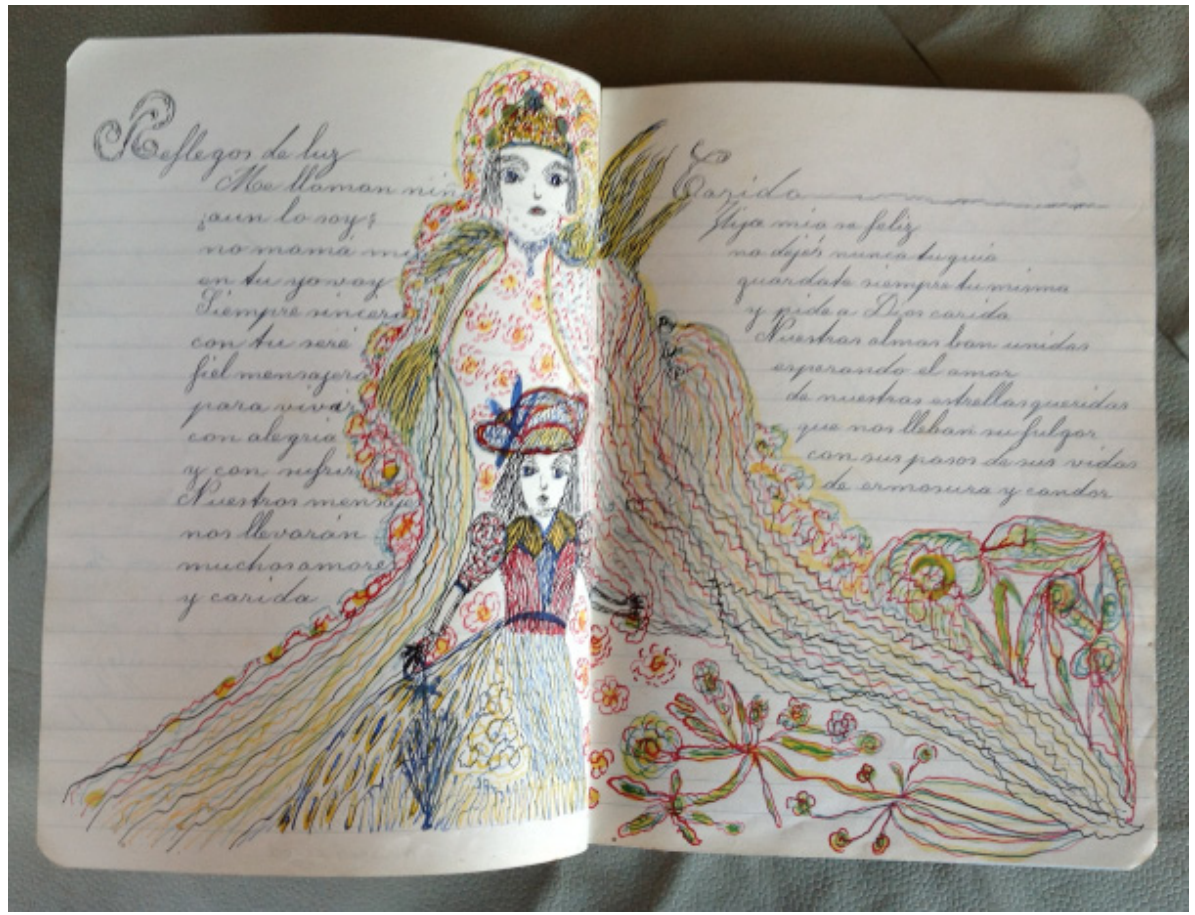

Figura 3. Libreta, 1944. Tinta, rotulador y bolígrafo sobre papel plegado y cosido, 28 x 17,5 cm. Colección particular Maria Tolrà 
la francesa Laure Pigeon (1882-1965), la suiza Enma Kunz(1892-1963) o la británica Magde Gill (1882-1961). Pertenece a esta misma generación de artistas con potencial psíquico y guiadas por los espíritus benefactores. Todas ellas tuvieron vidas complejas, pérdidas irremediables y experiencias multidimensionales entre el mundo material y los espacios espíritos. Mediante el dibujo y la sanación encuentran claves de acceso al más allá y otros vínculos con el cuerpo y la mente.

De entre las producciones de Josefa Tolrà, los escritos y las ilustraciones de las libretas son documentos excepcionales y enigmáticos (figura 3). Más de treinta cuadernos donde se expresa en castellano y catalán, con pulcra caligrafía y también con letra temblorosa y signos ininteligibles que recuerdan antiguos alfabetos o letras primordiales. Josefa sabe poco de literatura, pero transcribe los dictados de sus momentos de trance sin pausas ni correcciones. El primer cuaderno es del año 1941 y comienza así: «Hoi 30 de octubre de 1941» (sic). A partir de aquí, una serie de dibujos y caligrafías remontan las tinieblas para encontrar la luz. Pocos días después, toma nota detallada de las comunicaciones que lleva a cabo, no sabemos si de forma privada o por petición de otras personas. Como un registro de trabajo, recopila conversaciones y reflexiones sostenidas con las entidades espirituales, entre ellas, posiblemente, su hijo Pere, que aparece con las iniciales P.L1. (Pere Lladó). En otras ocasiones, escribe poemas, prosas, canciones, recetas curativas e historias que ilustra con retratos de personajes famosos, caligramas, ángeles y filigranas ornamentales. Los textos tratan sobre ciencia y religión, geografía o geología, temas que desconoce pero que los hermanos de luz le dictan. Son habituales las referencias y los retratos de Mossèn Jacint Verdaguer, con quien registra varias comunicaciones, siempre en catalán: «Comunicación con un hermano feliz. Día 4 Diciembre año 1942. Jacin Verdaguer (sic). Hermana por primera vez vengo a hablarte...». También destacan los escritos dedicados a la astronomía y su reflexión sobre la Tierra como «un planeta pequeño pero muy habitable». En los fundamentos espiritistas, existe la creencia de que la Tierra no es el único planeta con vida del universo y que los espíritus transitan por todos ellos a la búsqueda de la perfección: «Historia y analisis de los Planetas. La Tierra. Por ser la tierra un Planeta joven está basado muy fertilmente. Sus conductos Etereos pueden por si mismos emanar fuerzas prodigiosas...»» (sic). Los textos llevan epígrafes: «Narración sacada del más grande progreso Cristiano sacado a la luz con la ayuda de la Médium JT. Octubre año 1945». Este material es un archivo importante para interpelar el legado de la artista, conocer sus reflexiones y una particular melancolía creativa. 
Del mismo modo que dibuja, sin esbozo previo, Josefa Tolrà también hace bordados. Los motivos y las cenefas se configuran con cada puntada, como resultado de las indicaciones que ella presiente y traslada a la tela. A veces, en esta diligencia exclama: «imira qué me hacen hacer!». Como otras mujeres que han respondido a su potencial psíquico a través de dibujos y tejidos, canaliza los mensajes que llegan desde la dimensión multisensorial con cuidada laboriosidad femenina y doméstica. Siempre en casa y con la familia, poco dada a salir ni perder el tiempo, Josefa Tolrà se sienta en una pequeña silla para bordar (figura 4). No es una mujer excéntrica ni padece

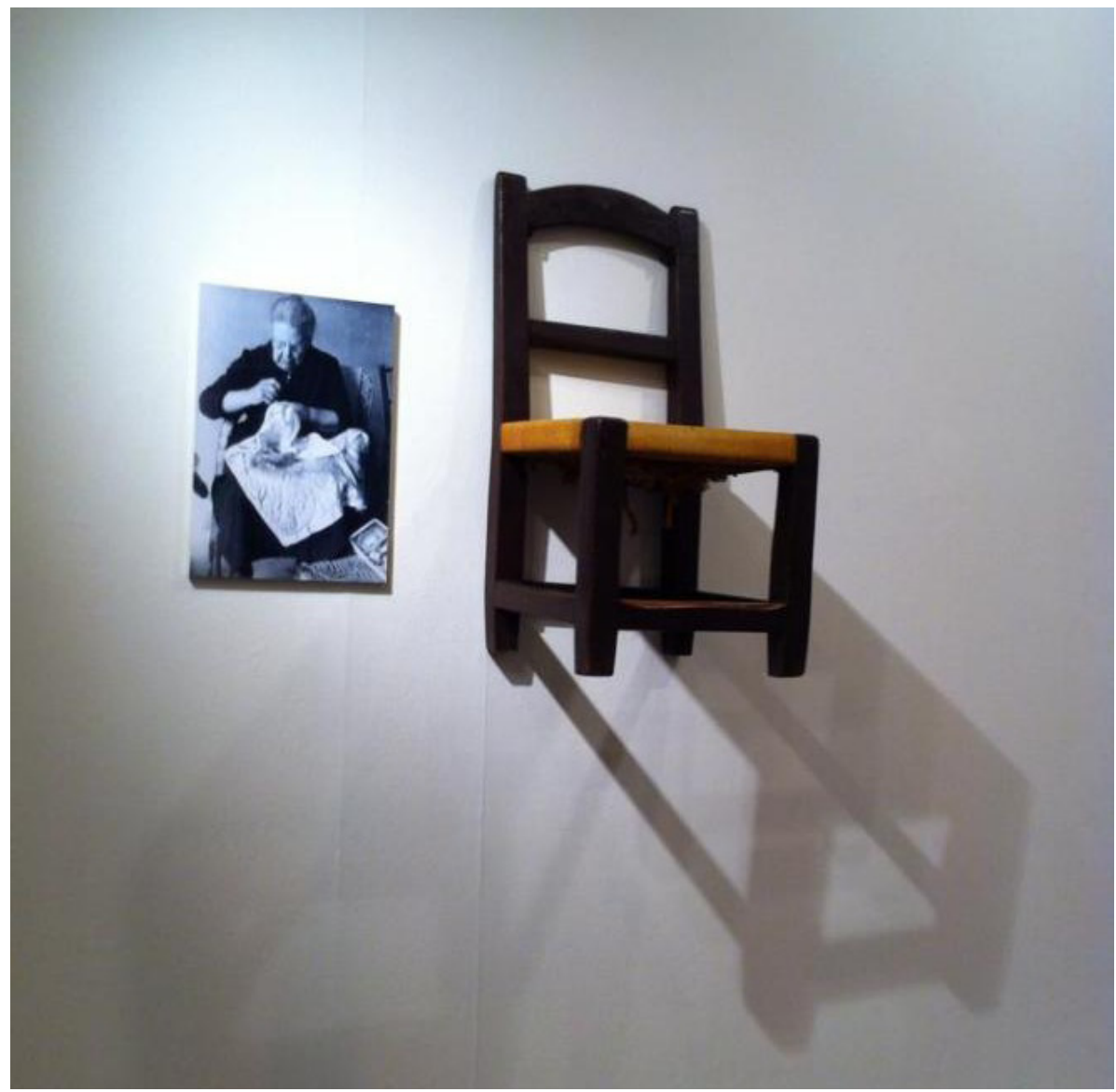

Figura 4. Fotografía de Josefa Tolrà bordando. Colección particular Maria Tolrà 
ningún rechazo social, es una persona familiar y perseverante que pasa las horas acompañada de sus «hermanitos». Cada puntada equivale a abrir los ojos a una profunda dimensión más allá de las cosas, el tiempo y el espacio. Las filigranas y figuras de seda tienen la marca de la gran tradición ornamental de todos los tiempos y una belleza universal que nos cautiva. Los bordados no tienen ni derecho ni revés, tal es su perfección.

\section{Dibujo Fuerza Fluídica}

Josefa Tolrà, Pepeta para la familia y amigos, jamás tuvo ambición de artista, ni comercializó sus dibujos. Dibujaba con delicadeza, sin convenciones académicas, pero con una extraordinaria capacidad gráfica para representar escenas, personajes e historias. En ocasiones, los dibujos hacen referencia a paisajes y figuras del entorno, como la escena de una sardana o el personaje con barretina catalana. En otros casos, las historias pasan en lugares remotos con protagonistas que ella retrata y nombra: Julio César, Leonardo da Vinci, Marconi o Bonaparte. Resulta una buena guía para la posible interpretación lo que escribe al margen del papel: Figura románica: la Esfinge (1954), El alma de la fantasía (1959) o La hija del faraón (s/d). Pero estas leyendas son mensajes herméticos para nosotros, preservan el secreto. Tan solo podemos intuir la evocación de mundos no materiales y la voz de los espíritus en medio de las huellas rutilantes de energía fluídica. Con este concepto de «energías fluídicas», firma la mayoría de sus dibujos: «Dibujo fuerza fluídica», siempre en castellano aunque sea una lengua que conoce poco. Los círculos y las espirales simbolizan esta fuerza.

Ya a finales del siglo xix, en toda Europa se había extendido la práctica del espiritismo y las sesiones de las mesas giratorias, enigmas de comunicación con los espíritus de los muertos. La energía magnética y la fluídica son una misma cosa entre los espiritistas. Como señala Gérard Audinet (2012), cuando se refiere a la necesidad de buscar el camino hacia los mundos sutiles que practicaba el escritor Victor Hugo (1802-1885), «hay un entusiasmo general por experimentar la comunicación no sensorial y explorar el inconsciente mediante el espiritismo, desde la pluralidad de mundos habitados». Casi una moda que el caricaturista Daumier ridiculizaba en unas divertidas litografías tituladas «Fluidomanie». Cuando Josefa utiliza el término «fluídico», entra de lleno en la dinámica de esta práctica esotérica y sus representaciones 
gráficas, vivencias absolutamente extravagantes a ojos de los escépticos. En los escritos, también hace referencia a la reencarnación y considera el progreso espiritual y científico como vías comunes para el desarrollo de la humanidad y la culminación de una verdadera fraternidad universal. Una de sus obras, la única en la que no aparece ninguna figura, se titula Dibujo basado con la luz del progreso científico Espiritual (1948). Postulados enraizados en el pensamiento espiritista y también en el anarquismo de la época. Los espiritistas afirman que los espíritus son seres inteligentes e inmortales que pueden conectarse a través de los médiums.

Allan Kardec (1804-1869), precursor de la doctrina de los espíritus, habla del agente fluídico como una forma de revelación, allí donde la ciencia física topa con lo maravilloso y desconocido: los fluidos imponderables, el cuerpo astral, los ectoplasmas y todo lo que emerge del poder de los magnetizadores, los sonámbulos y médiums.

Fenómenos que despertaron la curiosidad y apasionaron a escritores y artistas del romanticismo y, más tarde, del surrealismo: Balzac, Flaubert, Verne, Dickens, Hugo, Conan Doyle, Breton o Dalí, entre muchos otros. La energía magnética o fluídica es la misma que mueve las mesas giratorias y que la ciencia no reconoce como hipótesis racional, pero que los artistas validan como exploración del subconsciente. El cuerpo astral es para Kardec la energía fluídica suspendida en el infinito del universo después de la muerte, una parte de la consistencia doble de la materia. Una investigación en paralelo a la que la artista sueca Hilma af Klint practicaba en sus pinturas y dibujos, obra que hemos descubierto en una extraordinaria exposición donde la pintora y médium nos desvela los secretos del macrocosmos y el microcosmos. Josefa Tolrà pertenece a esta genealogía de mujeres místicas, una luminosa ontofonía creativa.

Los dibujos y las ilustraciones de Josefa Tolrà se han de entender en esta dimensión. Como proyecciones de la comunicación con el universo y sus astros: «Estrella rutilante que al pasar por su esfera deja un rastro de luz», explica al lado de un dibujo de energía fluídica. Algo cercano a lo que el parapsicólogo Baraduc (1913) exponía en su libro sobre la iconografía del invisible fluídico en la región de la luz, entre la ciencia y una ilusión paranormal hacia la investigación sobre la existencia del alma. Hablamos de experiencias a medio camino "entre lo cognitivo y lo afectivo" (Pierssens, 2007), aunque sabemos que conocimiento y sentimiento no pueden disociarse. Josefa Tolrà vive en este contexto temporal y espiritual. Seguramente, mantuvo contacto 
con personas relacionadas con los estudios de la teosofía o el espiritismo. ¿Artista o médium? Podemos afirmar que es una creadora que se deja guiar por los seres de luz y que transcribe sus comunicaciones orales en forma de poemas, conversaciones o relatos científicos. Comparte la afirmación de que la armonía del universo se dicta en una sola ley: el progreso en todo y para todos, como escribió otro médium artista, Victorien Sardou (1831-1908). Si existe una conciencia cósmica que permite a los médiums establecer comunicación con los espíritus y, al mismo tiempo, hay un archivo de memoria ancestral que ofrece a los humanos nuevos conocimientos, Josefa Tolrà es uno de estos casos de estudio.

Se pueden observar tres registros en la variada iconografía de las obras fluídicas de Josefa Tolrà: los dibujos y las ilustraciones con figuras, escenas y paisajes más costumbristas, evocaciones del mundo, de su entorno o de historias del pasado; los temas religiosos y bíblicos, con figuras de Jesús o la Madre de Dios y la Santa Cena; personajes y visiones relacionados con el mundo oculto, como figuras de mujeres médium, teósofas, seres astrales o visiones planetarias. En diferentes formatos, sobre papel de todo tipo o libretas escolares, los dibujos están ejecutados trasladando el oficio femenino del bordado a la línea de tinta. Josefa Tolrà dibuja igual que borda: puntadas gráficas que ejecuta con rapidez y sin modelo ni plantilla. Hay un cierto automatismo en el trazo repetitivo y ornamental. Dibuja, escribe y borda siempre con la misma minuciosidad y pulcritud. Las líneas nunca son rectas, el dibujo está hecho de puntadas con tinta o pincel, a base de superposiciones consigue el claroscuro de los volúmenes o la profundidad de campo. La frontalidad de las figuras, de gesto arcaico, y la perspectiva intuitiva de las escenas son inocentes y al mismo tiempo muy expresivas. Los dibujos están firmados y fechados, con una rúbrica que, a veces, se acompaña de pequeños seres ingrávidos, sin pies ni manos. Desde el dolor y la nostalgia, la autora se muestra sensible y capaz de potenciar su proceso creativo hallando en el tiempo artístico su paz interior, lo que ella denomina «meditación astral».

Josefa Tolrà es una mujer creyente, piadosa y caritativa que sigue los dictados de los «mensajeros de la buena voluntad» y el «divino maestro Jesús», como ella los describe. Cristiana y espiritista, ayuda a sus vecinos invocando al buen Dios y aconseja hierbas curativas a los enfermos. Jesús es, entre los espiritistas, el modelo y guía moral para la humanidad, ella lo invoca y representa en varias ocasiones, también en los momentos de sanación. Muchos de los dibujos reflejan su visión de la espiritualidad en figuras y 


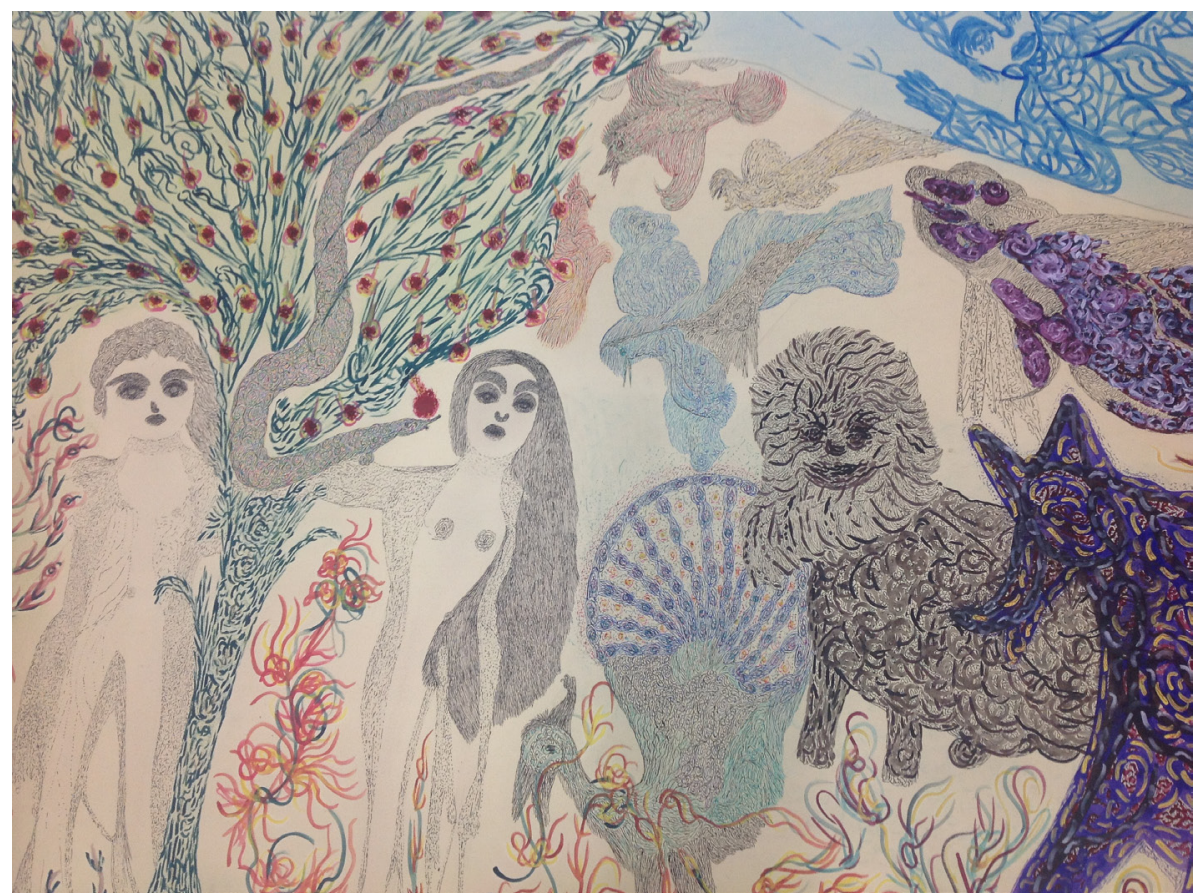

Figura 5. Adán y Eva, 1957 (detalle). Tinta, acuarela, gouache y rotuladores de colores sobre papel, 70 x $100 \mathrm{~cm}$. Museo Nacional Centro de Arte Reina Sofía

temas bíblicos, pasajes de los evangelios y alegorías místicas. La escena de la Santa cena (1955) o la representación del Edén, con las figuras desnudas de Adán y Eva (1957) (figura 5), son imágenes de extraordinaria belleza. El trazo del dibujo, la superposición de la pincelada, los detalles de las figuras y los ornamentos nos recuerdan el lenguaje de los bordados femeninos, las tradiciones ancestrales y las iconografías universales. Cada imagen dibujada por Josefa Tolrà es una trama de signos y símbolos primigenios y sagrados, llena de detalles que hay que mirar desde la distancia más corta para apreciar su profundidad. Los personajes siempre llevan la cabeza cubierta, signo de personalidad, solo la figura de Jesús va sin sombrero, él «no lo necesita», comenta Josefa. Su espiritualidad es natural, sin mediación institucional, sin rituales de iglesia ni curas. En varias ocasiones, recibió la visita de sacerdotes que querían saber sobre su videncia, pero nunca fue rechazada ni amonestada. 


\section{Los Artistas y la Médium}

Los dibujos de planetas, hadas, ángeles y figuras evanescentes son muy mistéricos y atraen de una forma poderosa. Están basados en la grafía de círculos dinámicos que se ramifican y enroscan sobre ellos mismos, expresión visual afín a la conexión que Josefa vive entre el mundo material y el astral. El dibujo fluye sin conceptualización previa, cuando la autora ha vivido en estado de vacío. Son psicografías que hay que leer desde fuera de la interpretación iconográfica tradicional. Vemos magníficas figuras transparentes, visiones planetarias, miradas de médiums, genios, aerolitos o diosas del fuego. Podemos destacar una serie de obras en las que recrea una galería de figuras femeninas de enorme belleza y ornamentación, con miradas de gran profundidad y un magnífico vestuario de encajes, bordados y mantones: Figura con mantón bordado (1946), Gran camino fluídico (1947) o Mujer con abalorios (1948).

La singularidad de su obra gráfica y el relato de tal experiencia sobrenatural no pasó desapercibida a los artistas Moisés Villèlia y Magda Bolumar, instalados en los años cincuenta en la pequeña población de Cabrils. Es posible que el escultor Villèlia, amigo de la gente del grupo cultural Club 49 y el círculo de los artistas de Dau al Set, pusiera en relación a Josefa Tolrà con el crítico Alexandre Cirici Pellicer y el poeta Joan Brossa. Ambos, admirados por la creatividad de Pepeta y su difícil clasificación estética, la visitaron en varias ocasiones y han dejado testimonio de estos encuentros en ediciones escritas y audiovisuales. Este es el vínculo que explica como el 18 de enero de 1956, en la sala Gaspar de Barcelona, se presentaron 12 dibujos de una autora desconocida, ajena a los círculos artísticos y literarios de la época: Josefa Tolrà. Los promotores de la exposición fueron la gente del Club 49, y el crítico de arte Cirici Pellicer fue el encargado de hablar sobre los dibujos, los dichos y los hechos de una mujer de Cabrils que poseía una energía psíquica excepcional como médium y artista. El psiquiatra Joan Obiols, miembro del grupo y experto en dibujos de enfermos mentales como materiales de estudio clínico, fue el encargado de seleccionar los dibujos.

Aquella exposición fue nocturna y clandestina, los dibujos eran la muestra de una catarsis plástica extraordinaria. Los invitados formaban parte del círculo de artistas del grup Dau al Set, expertos y amantes de los mundos sutiles. A lo largo de los años cincuenta, mucha gente del arte la visitó en la masía de Cabrils para admirar los dibujos y sus discursos sobre ciencia, filosofía o historia. Entre ellos, los artistas Modest Cuixart y, posiblemente, 
Antoni Tàpies, la escritora Maria Dolors Orriols, el poeta Enrique Modolell o el dibujante Manuel Cuyàs. Actualmente, sus dibujos forman parte de tres colecciones internacionales de arte contemporáneo en Barcelona, Madrid y París: MACBA, MNCARS y el LaM. A pesar de este itinerario internacional de las obras, la vida y la creatividad de Josefa Tolrà siguen en el espacio del misterio. Ahora, 54 años después de su muerte, se ha presentado en Mataró, muy cerca de Cabrils, la exposición más completa que jamás se ha podido ver de los dibujos, textos y bordados de Josefa Tolrà, «la maravillosa dibujante Pepeta de Cabrils», como la llamó Cirici Pellicer. Su obra, prácticamente desconocida, su espiritualidad y bondad nos invitan a repensar muchos aspectos sobre la vida y el misterio de las imágenes, la experiencia mística de las mujeres, el arte y la mediumnidad.

El poeta Joan Brossa nos ha legado un documento audiovisual sobre la persona de Josefa Tolrà de enorme interés. No es extraño que el poeta se sienta fascinado por la médium Josefa Tolrà, ya a inicios de los años cuarenta estudió psicología y psicoanálisis, siguiendo a Freud e interesado por el automatismo psíquico y las imágenes hipnagógicas. Conocedor de la aventura del surrealismo y la figura de Breton siempre mostró gran interés por el universo que emerge del inconsciente y las creaciones de visionarios y locos. Fascinado por el magicismo, el ocultismo, la cultura popular y la tradición hermética, Brossa siguió con atención la creatividad de Josefa Tolrà. $\mathrm{Su}$ testimonio nos relata una relación de afinidad y complicidad con la artista y médium de Cabrils, quien desde el primer encuentro ve en el poeta un espíritu especial que describe en estas palabras: "Tu, fillet, estàs molt a prop de Déu, però hi estàs d'esquena..." (Tu, hijo, estás muy cerca de Dios, pero estás de espaldas...). Joan Brossa relata hechos y anécdotas de Josefa Tolrà, destaca su humildad y falta de interés comercial como artista, comentando que ella regalaba sus obras a quienes la necesitaban, tras consultar con sus guías espirituales. El lenguaje visionario de la Pepeta atrae al poeta y recuerda alguna de las sentencias que expresa en diversas visitas de artistas: El arte es un correo de tipo práctico.

\section{El Pensamiento Lateral: Arte de los Enfermos Mentales, Art Brut y Outsider Art}

La pulsión creativa de Josefa Tolrà fascina a artistas y vecinos. Su peculiar práctica gráfica avanza de las formas más sencillas a las más complejas. De los primeros garabatos casi ininteligibles de la primera libreta encontrada de 1941, 
pasa a una pulcra caligrafía en pocos meses. Asimismo, los primeros dibujos son negaciones gráficas, espacios de oscuro cromatismo donde podemos descubrir rostros o incluso cartografías que perfilan continentes y océanos. En pocos meses su obra alcanza la claridad lineal, explosiona la luz y las escenas son más narrativas. Pero no se trata de dibujos de una alienada, diagnosticada con una patología mental, como los que recopiló el psiquiatra Hans Prinszhorn entre 1919 y 1921 como documentos clínicos para elaborar un estudio sobre el misterio de la creación. ${ }^{4}$ Este historiador del arte y psiquiatra potenció y estudió las actividades artísticas entre los enfermos mentales, pero también reconoció las diferencias entre un artista y un esquizofrénico: si el primero, aún y siendo un personaje solitario, mantiene el contacto con la humanidad, desde el deseo y la nostalgia, el esquizofrénico no quiere contacto alguno y vive en el solipsismo.

Nos atrae el arte fuera de norma, como los dibujos de los alienados mentales, porque nos pone en contacto con nuestro lado oscuro y misterioso. Cuando un artista está más aferrado a sus experiencias personales más contacta con el espectador, su psique nos oferta un recorrido intuitivo y su producción nos magnetiza. La obra de Josefa Tolrà nos fascina igual que los dibujos de los enfermos psíquicos o de los niños por su singularidad fuera de orden, pero debe considerarse desde una capacidad espiritual, espontánea y feliz que los distingue y diferencia de entre las creaciones clasificadas en estos registros de marginación (Thévoz, 1990). Por eso mismo, en esta bondad mística que guía su obra, no la podemos emparentar con la clasificación convencional de arte bruto que acuñó el artista Jean Dubuffet en 1945 y que, desgraciadamente, acaba definiendo formas de expresión propias de personas consideradas como locas, marginales o extravagantes ${ }^{5}$. El artista Dubuffet aplica el término que el mismo acuña de art brut a las producciones de todo tipo, dibujos, pinturas, bordados, figuras modeladas o esculpidas, que presentan un carácter espontáneo y fuertemente inventivo, poco deudoras del arte acostumbrado a los tópicos culturales y que tengan por autores a personas foráneas de los ambientes artísticos profesionales. Pero, Josefa Tolrà no es un personaje perturbado por desequilibrios mentales, no padece ninguna exclusión social como una outsider ni tampoco vive de manera excéntrica fuera del orden o la moral, como designa Roger Cardinal a los autores fuera de norma ${ }^{6}$. Más bien al contrario, Pepeta es bondadosa y caritativa, ayuda a sus vecinos y pasa las horas trazando mágicos caligramas en dibujos y libretas. Sabe que bajo la apariencia material hay un mundo interconectado que emerge y se transforma desde las conexiones cósmicas. Accede a él a través de los guías espirituales 
y solo con propósitos dignos y con elevada vibración. Josefa, con el don de la imagen y el verbo, consigue así reconfortarse en el dolor por la pérdida de los seres queridos: «Soy como una mariposa y con mis alas voy a la estrella Marte sintiendome frajil pero tambien fuerte» ( $\mathrm{sic}$ ).

Josefa Tolrà dibujaba y escribía sin presión estética ni literaria, tan solo como mediadora entre el mundo material y el espiritual, y titulaba las obras como «dibujo fuerza fluídica». Una creatividad que el museo o la historia del arte no pueden clasificar porque queda fuera de norma y se escapa de toda mirada autoritaria. Su legado, los dibujos y los textos, nos enseñan a ver de nuevo y entender que su experiencia también construye la gran enciclopedia del saber contemporáneo desde los campos interdisciplinarios de la historia, el arte, la literatura, las ciencias humanas y la medicina. El caso de Josefa Tolrà, junto a otras mujeres artistas, nos regala un extraordinario espacio de estudio en la alteridad del mundo contemporáneo.

\section{Notas}

1 Martínez, Ch. La gran transformación. Arte y magia táctica. (2008). Rotterdam: Veenman cop. Catálogo de la exposición.

2 Müller, I. (ed.) Hilma af Klint. Pionera de la abstracción. (2013). Málaga: Museo Picasso. Catálogo de la exposición.

3 Bonet, P. (ed.) Josefa Tolrà. Médium i artista (1880-1959).Mataró: ACM / Ajuntament de Mataró. Catálogo de la exposición.

4 Prinzhorn, H. (2012). Expresiones de la locura, el arte de los enfermos mentales. Madrid: Cátedra.

5 Fauchereau, S. (ed.). (2006). En torno al Art Brut. Madrid: Cículo de Bellas Artes.

${ }^{6}$ Cardinal, R. (1972). Outsider Art. NY: Praeger.

\section{References}

Audinet, G. (2012). "L'art de la table" Entrée des médiums. Spiritisme et art de Hugo à Breton. Paris. Maison de Victor Hugo. 11-25.

Baraduc, Dr. H. (1913). "Iconography of the fluidic invisible", The Human

Soul. Paris. Librarie Internationale de la Pensée Nouvelle.

Bonet, P. (2014). ¿Quién duerme con Hilma af Klint?. A*Desk, 6-2-2014.

Recuperado de http://www.a-desk.org/highlights/Quien-duerme-con- 


\section{Hilma-af-Klint.html}

Pierssens, M. (2007). "Fluidomanie", Romanticisme 4 (n.138). 75-88.

Recuperado de www.cairn.info/revueromanticisme-2007-4-page-75 Thévoz, M. (1990). Art Brut, psycose et médiumnité. Paris. La Différence. $140-148$.

Pilar Bonet: Profesora Colaboradora del Departamento de Historia del Arte de la Universidad de Barcelona. Investigadora y docente en arte y diseño contemporáneo, y en crítica de arte. Comisaria de exposiciones.

Contact Address: Facultad de Bellas Artes. Universidad de Barcelona. Departamento de Historia del Arte. c/ Pau Gargallo 4, 08028 Barcelona (España).

E-mail address: pilarbonet@ub.edu Web: www.pilarbonet.com/inicio 